Institute of $\mathbf{F}_{\text {ood and }} \mathbf{A}_{\text {gricultural }} \mathbf{S}_{\text {ciences }}$

\title{
Manual de los Regalmentos del Agua de Florida: Poderes Reguladores del Estado ${ }^{1}$
}

\author{
Michael T. Olexa, Laura Minton, Dulcy Miller, y Sarah Corbett ${ }^{2}$
}

\section{Agradecimientos}

Los autores agradecen a Richard Budell de la Oficina de Política del Agua Agrícola del Departamento de Agricultura y Servicios al Consumidor de Florida. Los autores también agradecen a David H. Hammonds, Consultor del Programa de Salud Ambiental, Oficina de Programas de Aguas de Drenaje en el Sitio, del Departamento de Salud de Florida, y a Edward A. Bettinger, Consultor del Programa de Salud Ambiental, Oficina de Programas de Agua del Departamento de Salud de Florida.

\section{Sinopsis de las Leyes del Estado}

La ley del estado llena los espacios y complementa a la ley federal. La ley del estado también a menudo duplica a la ley federal. En muchos casos, sin embargo, los estándares de la ley estatal son más estrictos que los de la ley federal. Consecuentemente, obedecer las leyes estatales a menudo asegura también actuar en cumplimiento con las leyes federales. En conciso, las leyes estatales toman dos formas: estatutos y reglas administrativas.

\section{Estatutos}

Los estatutos son aprobados por la legislatura del estado, y establecen las metas básicas de la legislatura y los procedimientos que ella quiere

1. Este es el documento EDIS FE064, una publicación del Department of Food and Resource Economics, Florida Cooperative Extension Service, Institute of Food and Agricultural Sciences, University of Florida, Gainesville, FL. Publicada Noviembre 2002. Por favor visite la página electrónica EDIS en http://edis.ifas.ufl.edu.

2. Michael T. Olexa, es profesor del Department of Food and Resource Economics, Florida Cooperative Extension Service, Institute of Food and Agricultural Sciences, University of Florida, Gainesville, FL; y miembro de Florida Bar; Presidente de Agricultural Law Committee of The Florida Bar; y Director del Agricultural Law Center. Laura Minton, Dulcy Miller, y Sarah Corbett son estudiantes graduadas de Levin College of Law, University of Florida, Gainesville, FL. Filiberto Reyes-Villanueva fue el traductor de la versión en ingles al español.

Esta publicación esta diseñada para proporcionar información precisa, actualizada y autorizada sobre esta material. Sin embargo, ya que las leyes, reglas administrativas y decisiones de la corte, sobre las cuales están basados, están sujetas a revisión constante; algunas partes de esta publicación podrían ser obsoletas en cualquier momento. Esta publicación es distribuida bajo el entendimiento que los autores no están involucrados en ninguna representación legal u otros servicios profesionales, y que la información contenida aquí no debe ser considerada como un substituto de una asesoria legal. Esta publicación no esta completa en proporcionar toda la información para lograr el cumplimiento de las leyes y reglamentos que gobiernan la protección del agua. Por estas razones, el uso de estos manuales por cualquier persona constituye un acuerdo para mantener libre de daño a los autores, al Florida Cooperative Extension Service, al Institute of Food and Agricultural Sciences, y a la University of Florida por cualquier demanda por responsabilidad de daños, o gastos en que pueda incurrir cualquier persona, como un resultado de hacer referencia o confianza sobre la información contenida en esta publicación. Esta publicación fue apoyada financieramente por el Florida Department of Agriculture and Consumer Services.

El Instituto de Alimentos y Ciencias Agrícolas es Un empleador que opera bajo Acción Afirmativa y provee Oportunidades Igualitarias, dedicado a promocionar la investigación, a información educativa y otros servicios, únicamente a los individuos e instituciones que operan baj discriminación sin considerar color, raza, sexo, edad, incapacidad u origen. Para más información sobre como obtener otras publicaciones de la extensión, comuníquese con la oficina de Servicio de Extensión de su condado. Servicio de Extensión de la Florida / Instituto de Alimentos y Ciencias Agrícolas / Universidad de la Florida / Christine Taylor Waddill, Decana. 
aplicar para lograr estas metas. Aunque los estatutos a menudo proporcionan instrucciones y prohibiciones muy específicas, muchos detalles de regulación en un área de negocios o un aspecto del medio ambiente, son frecuentemente muy técnicos y detallados como para que la legislatura los aborde.

\section{Reglas Administrativas}

La legislatura generalmente se basara en agencias administrativas para conseguir sus metas específicas. Para hacer esto, la legislatura autoriza a las agencias administrativas a adoptar reglas (las cuales tienen fuerza de una ley) dentro de los límites estrechos de las instrucciones dictadas por la legislatura.

Por ejemplo, si la legislatura decidió que hubo un interés del estado para regular el uso de ciertos plaguicidas, puede aprobar un estatuto que ampliamente defina los usos o prohibiciones del plaguicida, luego lo pasa a una agencia (en este caso el Departamento de Agricultura y Servicios al Consumidor), para que haga reglas acerca de cuando, por quien, y en que cantidades el plaguicida deberá ser aplicado. En la mayoría de los casos, las agencias también tienen el poder para imponer sus reglas a través de castigos civiles y penales, así como también mediante regulaciones para permisos/ licencias.

\section{¿Cómo Están Restringidas las Acciones del Estado y del Gobierno?}

Para asegurar que las agencias cumplan con justicia con las personas sujetas a sus regulaciones, Florida ha aprobado las siguientes leyes:

- Acta de Procedimiento Administrativo de Florida (Capitulo 120, Estatutos de Florida). Esta Acta establece muchos derechos de procedimientos tales como:

1. el derecho de ser escuchado por la agencia.

2. el derecho de recibir noticias de las acciones de la agencia.
3. y una oportunidad garantizada para que aquellos quienes son más afectados, usen esos derechos.

Este estatuto constituye el principal mecanismo para que opiniones privadas actúen y tomen parte en las acciones y reglamentación de la agencia.

- Ley de Registros Públicos de Florida (o Capitulo 119, Estatutos de Florida). Este estatuto permite que todos los registros de las agencias, con algunas excepciones legales, estén disponibles para la inspección y copiado por el publico. Las excepciones se originan cuando la confidencialidad de la información, es necesaria para una administración eficiente del gobierno o cuando la revelación afectaría adversamente la aplicación de la ley.

- Ley del Sol Reluciente de Florida (Capitulo 286, Estatutos de Florida) declara que todas las reuniones de cualquier organismo gubernamental en donde cualquier acción oficial es tomada, debe estar abierto al público y las minutas deben estar archivadas. Este estatuto, no es una garantía incondicional de acceso al gobierno, sino que en realidad falta un largo camino para lograr que los cuerpos administrativos sean accesibles al público.

\section{¿Cuál es la Estructura de las Agencias de Florida?}

La mayoría de las agencias estatales tienen estructuras similares. La mayoría tienen sus oficinas centrales en Tallahassee, y oficinas regionales a través de todo el estado. Dentro de cada agencia, puede haber diferentes divisiones y cada una con sus propias responsabilidades (como otorgar permisos, sancionar, y brindar información pública. Muchas agencias están encabezadas por un secretario quien esta en contacto directo con el gobernador. Otras agencias son dirigidas por un funcionario del gabinete o un comisionado designado. Todas están en contacto directo con la legislatura, para estar bien informadas acerca de los cambios en la política y mantener reglas precisas y actualizadas. 
La estructura de los gobiernos de la ciudad y del condado varían de gobierno a gobierno, pero cada uno tiene sus propias divisiones, desde las áreas rurales mas pequeñas hasta las áreas urbanas mas pobladas. Los condados y las ciudades están encabezados por una comisión electa. Algunas cuentan con administradores profesionales que se encargan de los aspectos diarios del gobierno, mientras que otras están basadas en funcionarios electos. 